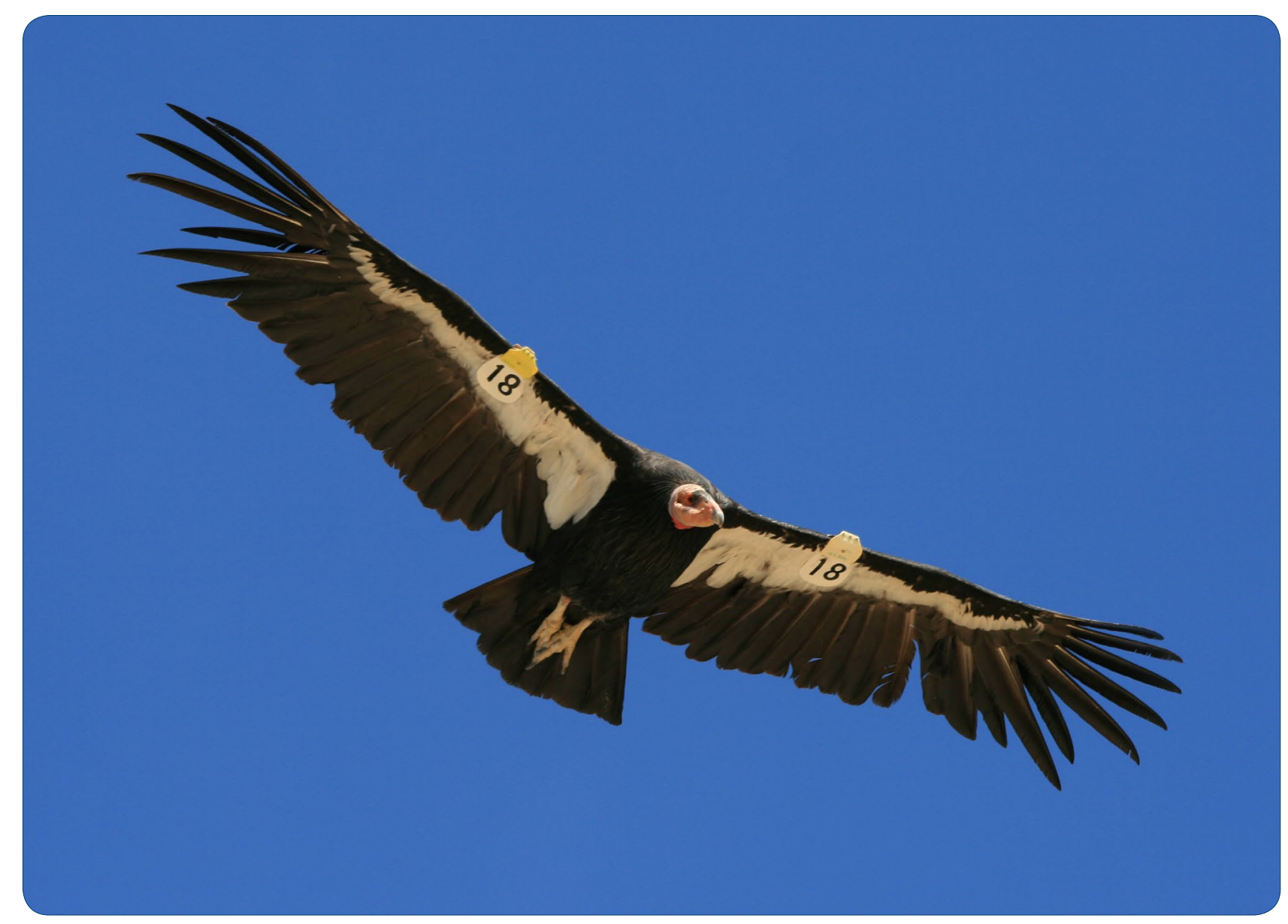

\title{
An autonomous GPS geofence alert system to curtail avian fatalities at wind farms
}

Sheppard et al. 


\title{
An autonomous GPS geofence alert system to curtail avian fatalities at wind farms
}

\author{
James K. Sheppard ${ }^{1 *}$, Andrew McGann², Michael Lanzone² and Ronald R. Swaisgood ${ }^{1}$
}

\begin{abstract}
Background: Wind energy developments are increasingly proliferating as nations seek to secure clean and renewable energy supplies. Wind farms have serious impacts on avifauna populations through injuries sustained by collisions with turbines. Our aim was to develop new biotelemetric technologies to minimize collision risks, particularly for threatened and endangered bird species whose ranges overlap with current and future wind farm sites.

Results: We report on the development and application of an autonomous alert system that successfully miniaturizes and integrates virtual geofence capability into solar-powered biotelemetry devices used to track species of large birds currently impacted by wind farms, such as cranes and raptors. These units combine a GPS receiver with a GSM communications system that transmits acquired high-resolution location data via cellular networks in near real-time. Custom sized geofences can be placed around wind farms. When a telemetered bird ingresses one of these virtual boundaries the GPS location fix rate decreases from 15-min to $30 \mathrm{~s}$ and an SMS alert is automatically transmitted to a user group within 2-min. When the bird egresses the geofence zone, a second alert is sent and the fix rate returns to 15-min to conserve transmitter energy and data acquisition costs.
\end{abstract}

Conclusions: Combining GPS level accuracy, a high fix sampling rate, location data received in near real-time, and automated SMS alerts into an integrated, flexible and cost-effective geofence biotelemetry system will provide conservation managers and wind farm operators with sufficient warning and time to implement mitigative actions to curtail avian collision fatalities.

Keywords: GPS telemetry, Geofence, Wind energy, California condor, Raptor, Autonomous alerts, GSM

\section{Background}

Wind energy developments continue to proliferate globally as nations seek clean and renewable alternative energy sources to fossil fuels. However, wind farms do not come without environmental costs [1]. A growing literature is documenting the serious impacts that wind farms can have on resident and migratory avifauna populations through mortalities from direct collisions with turbines [2, 3]. Recent estimates indicate that wind farms in North America are responsible for up to 368,000 bird fatalities annually [4]. Consequently, the development and implementation of effective measures to reduce wind energy impacts on wildlife is recognized as a top priority

\footnotetext{
*Correspondence: jsheppard@sandiegozoo.org

1 San Diego Zoo Institute for Conservation Research, Escondido, CA, USA Full list of author information is available at the end of the article
}

by biologists, conservation organizations, regulators and the private sector (see reviews by [5-7]).

Recent rapid advances in the miniaturization, accuracy and utility of biotelemetry devices [8] offer technological solutions to the challenge of reducing bird fatalities at wind farms. Our aim was to successfully develop and demonstrate a biotelemetry system that would provide automated alerts to select recipients if a telemetered bird flew within proximity of a wind farm so that appropriate measures could be taken in sufficient time to minimize the risk of collision injury. We built in and programmed real-time virtual fence (geofence) technology into prototype avian GPS-tags to provide this early-warning capability for large bird species such as eagles, vultures and cranes that have been documented suffering collision injuries from wind turbines [3, 9]. Golden eagle populations in North America appear to be declining [10], and Pagel et al. [11] found a minimum of 67 golden

\section{Biomed Central}

(C) 2015 Sheppard et al. This article is distributed under the terms of the Creative Commons Attribution 4.0 International License (http://creativecommons.org/licenses/by/4.0/), which permits unrestricted use, distribution, and reproduction in any medium, provided you give appropriate credit to the original author(s) and the source, provide a link to the Creative Commons license, and indicate if changes were made. The Creative Commons Public Domain Dedication waiver (http://creativecommons.org/ publicdomain/zero/1.0/) applies to the data made available in this article, unless otherwise stated. 
eagle mortalities at 32 wind energy facilities in 10 states between 1997 and 2012. Global populations of vultures are declining precipitously from anthropogenic threats [12], and recent studies indicate that mortalities from wind turbine collisions are an increasing impediment to their recovery [13]. The geofence system offers a unique technological solution to mitigate wind turbine collisions with these threatened species.

A geofence is a virtual boundary delineated around an area of interest that triggers: (1) A cue to the telemetered animal (e.g. electric shock); (2) a change in the location fix rate attempted by the unit, or; (3) an alert to managers whenever the animal crosses the boundary edge. Geofences are increasingly recognized as an effective platform to enhance the spatiotemporal flexibility of wildlife management. For example, geofences have been successfully integrated into the management of mammalian populations that come into conflict with or are disturbed by human activities, such as elephants and wolves (see review by [14]). However, until now geofence alert technology has been prohibitively too large or too complex to incorporate into avian biotelemetry. We report on the first autonomous GPS geofence alert system custom developed specifically for avian applications with a view to minimizing the risk of bird collisions with wind turbines.

\section{Methods}

\section{Technical specifications}

The transmitter model we developed to incorporate a geofence alert system was a CTT-1050a-PM Series GPS-GSM (2 Gen), Advanced Bird Telemetry System from Cellular Tracking Technologies ${ }^{\mathrm{TM}}$, LLC. These tags weigh $\sim 50 \mathrm{~g}$ and are $80 \mathrm{~mm} \times 62 \mathrm{~mm} \times 10 \mathrm{~mm}$ $(\mathrm{W} \times \mathrm{L} \times \mathrm{H})$. The tags are encased in a sturdy, weatherproof and nitrogen-purged polycarbonate $+\mathrm{ABS}$ thermoplastic housing. The antennae are internal to the hermetically sealed housing to improve ergonomics and aerodynamics. The tags can be configured as a backpack mount for large birds such as eagles, as a legmount device for long-legged species like cranes and herons, or as a patagial mount for condors (Fig. 1). The units are powered by a solar-recharging Lithium Ion Polymer (LiPo) battery pack and have an estimated operational lifespan of $>5$ years with a recommended operational temperature range of -40 to $85^{\circ} \mathrm{C}$.

GPS data are collected from sunrise to sunset, with start/stop times calculated from an astronomical formula based on the unit's GPS coordinates. Under unobstructed skies the fix rate is near $100 \%$. Location accuracy is rated at $<2.5 \mathrm{~m}$ horizontal, $<25 \mathrm{~m}$ vertical, $<0.001 \mathrm{~m} / \mathrm{s}$ velocity and heading. If cellular coverage is unavailable, the unit can store $>100,000$ fixes until it reacquires a GSM link.

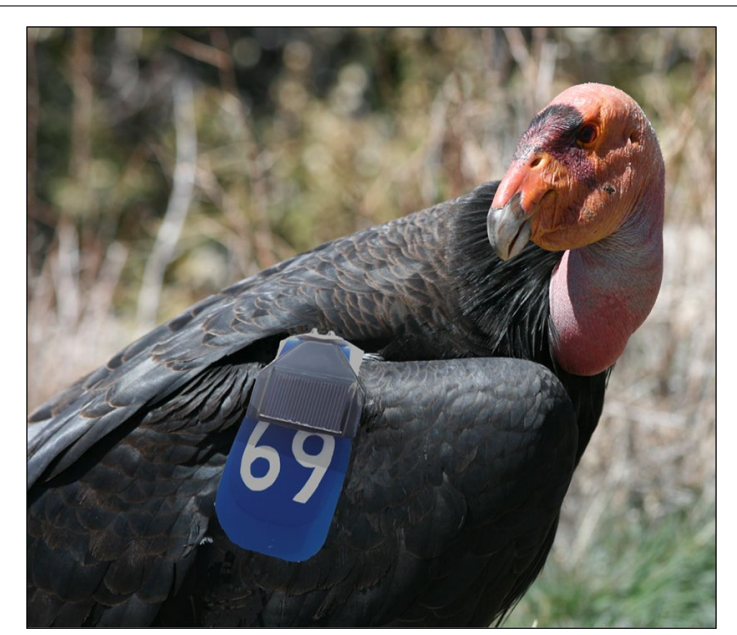

Fig. 1 Solar powered GSM-GPS geofence avian transmitter. Telemetry device is attached to the wing of a free-ranging California condor via patagial mount with an ID tag

The tags deplete their batteries if subjected to long periods of inclement weather with no recharging. However, if battery voltage falls to $\sim 3.6 \mathrm{~V}$, the tags conserve energy by ceasing daily GSM transmissions while continuing to collect GPS data. If power is $<3.5 \mathrm{~V}$, the tags enter a hibernate/recovery mode where all operations cease until they can recharge in sunlight.

Tag location data and diagnostic information are accessed from a secure CTT webpage. Acquired GPS location data are transmitted via a quad band GSM/ GPRS Class 10 850/900/1800/1900 MHz world band radio. Maximum output power is Class 4 (2 W) @ $850 / 900 \mathrm{MHz}$, Class 1 (1 W) @ 1800/1900 MHz. The GSM cellular system allows the device to frequently update large batches of data at considerably lower costs than satellite-transmitting devices using Argos or Iridium systems. The two-way communication of the GSM cellular system also enables the tag duty cycle and firmware to be reprogrammed post-deployment while the tags are attached to free-ranging birds. The GPS fix rate interval is set at 15 -min to provide a conservatively optimized balance between temporal resolution, power consumption, and data acquisition costs. Collected location data are transmitted once per day at noon PST. If a telemetered bird enters a geofence zone, the unit will transmit the most recent batch of data and the GPS fix rate will increase to $30 \mathrm{~s}$. When the bird exits the geofence zone, the GSM system will again transmit the most recent batch of data and the fix rate will return to 15 -min (Fig. 2). The two-way communication system enables the addition or modification of geofences as new management challenges present. Geofences can include up to three polygons consisting of up to eight vertex points 


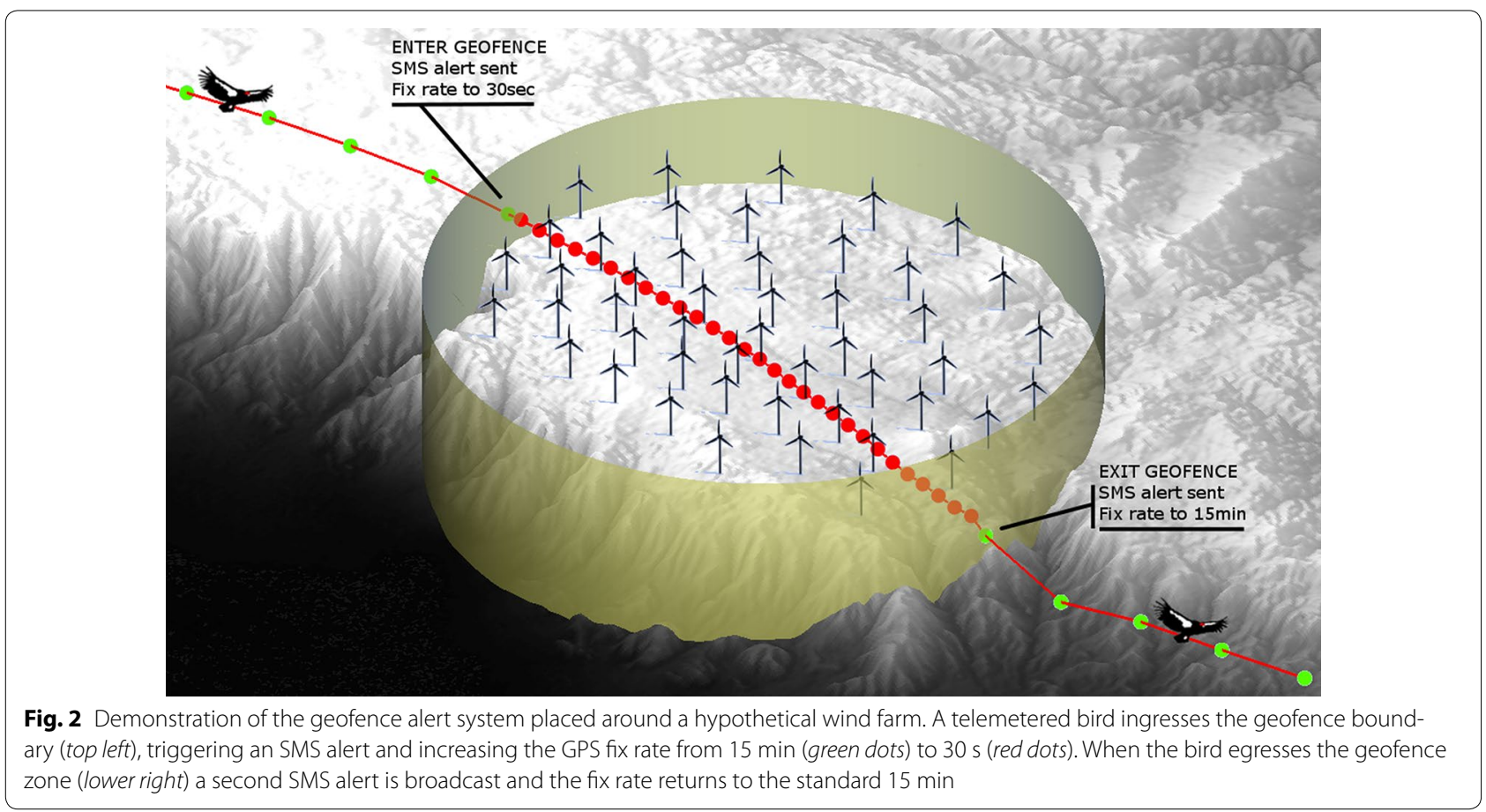

each, as well as three circular geofences. A video animation demonstrating the geofence system can be found at this link: http://youtu.be/2oWodZpmbHo.

\section{Performance field-testing}

We field tested the efficacy of the prototype units geofence tags by driving them across geofences in a car and by flying the tags in a helicopter along the flight path of a California condor (Gymnogyps californianus) that we previous tracked via GPS telemetry. This condor was from a population reintroduced to northern Baja California, Mexico, by San Diego Zoo Global and its partner organizations [15]. As the condor flew north along ridgeline of the Sierra Mountains of Baja and crossed over the USA/Mexico international border in April 2007, its interpolated flight path intersected the Energía Sierra Juárez Wind-energy Project (ESJWP) being jointly developed by IEnova and Intergen [16, 17] (Fig. 3). Although no direct condor injuries or fatalities from wind turbine collisions have been confirmed to date, they are considered a species at high risk from wind energy impacts [18]. The ESJWP may pose a collision injury risk to the recovering condor population in Baja. Therefore, we programed into the GSM/GPS tag server two concentric circular geofences around the ESJWP site spaced $20 \mathrm{~km}$ $\left(\right.$ area $\left.=1256 \mathrm{~km}^{2}\right)$ and $40 \mathrm{~km}\left(\right.$ area $\left.=5023 \mathrm{~km}^{2}\right)$ apart.

The spatial dimensions of the two geofence zones were based on the mean flight speeds $(15 \mathrm{~km} / \mathrm{h})$ recorded from the telemetered condor population in Baja and were calculated to give wind farm operators sufficient warning to slow or shut down turbines if a condor crosses the geofences and flies towards a wind farm. If a condor crosses the outer $40 \mathrm{~km}$ geofence boundary it will trigger an automated SMS message sent to a list of select recipients. This alert relays the bird's ID and geographic position relative to the wind farm site so that managers and wind farm operators can closely monitor its flight profile. If the condor continues and crosses the inner $20 \mathrm{~km}$ geofence zone a second SMS alert will be triggered indicating that the bird has flown into close proximity to the wind farm, prompting appropriate collision countermeasures. The 47 turbines installed at the ESJWP are Vestas ${ }^{\mathrm{TM}}$ model V112-3.3 with 112 m diameter rotors (3.3 MW) installed on $84 \mathrm{~m}$ towers. The average capacity of wind turbines installed in the US in 2012 was $1.95 \mathrm{MW}$ [19], so those installed at the ESJWP lie at the larger end of the turbine scale. It will take 30-60 s to bring an ESJWP turbine to a full stop once the command has been implemented (IEnova, pers. comm. 2015).

We matched the helicopter speed, height and trajectory to the flight path characteristics of the tracked condor that crossed the ESJWP site so that we could gauge how quickly the geofence system would respond to the ingress of a simulated telemetered bird. We flew at the maximum speed $(47 \mathrm{~km} / \mathrm{h})$ that we recorded for the condor and at its mean flight height ( $1240 \mathrm{~m}$ above mean sea level, $400 \mathrm{~m}$ above ground). We tracked our flight path at submeter accuracy using a Juniper Systems ${ }^{\mathrm{TM}}$ Archer Field 


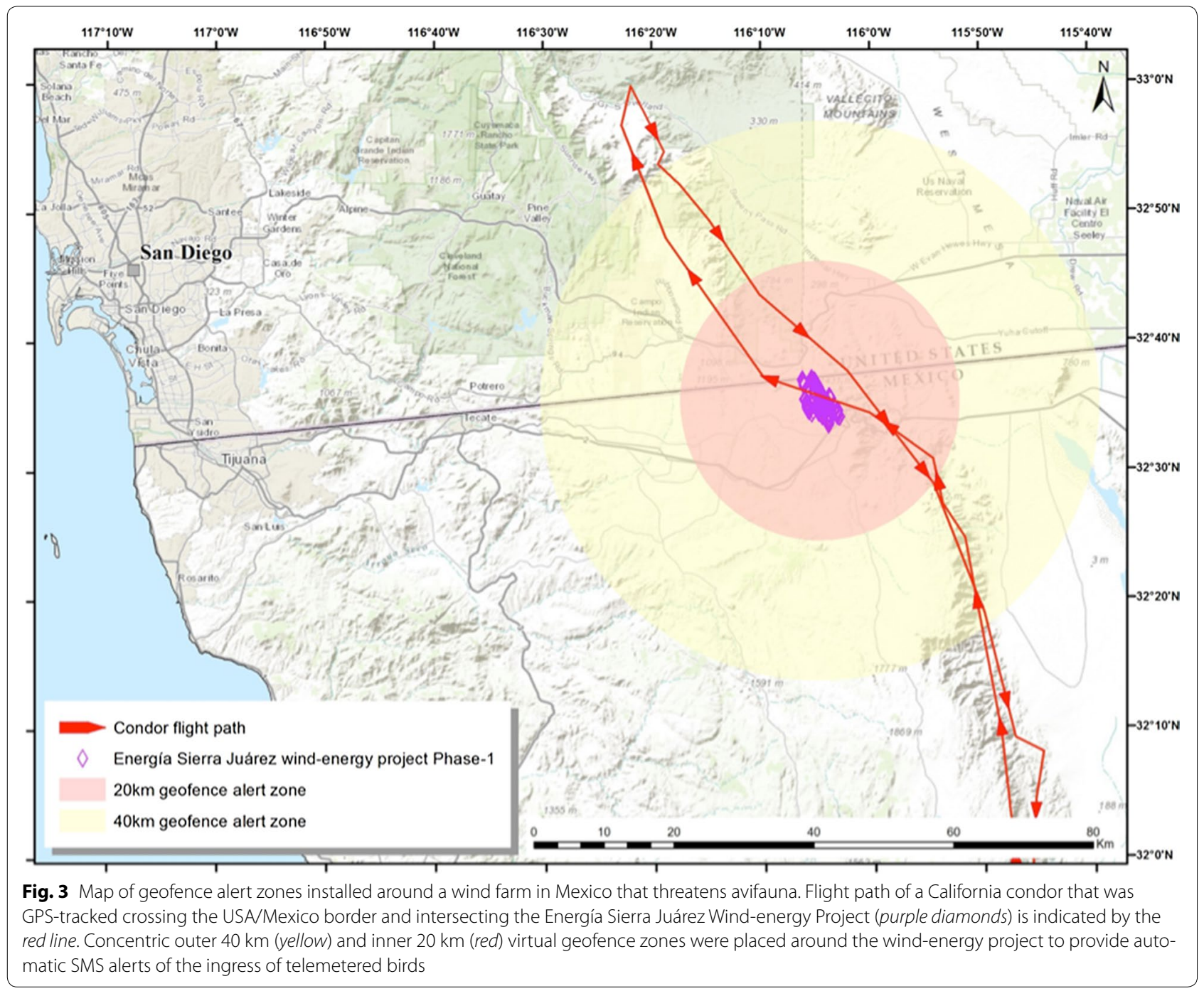

PC GPS connected to a Hemisphere ${ }^{\mathrm{TM}}$ GPS XF101 DGPS receiver running $\operatorname{ArcPad}^{\mathrm{TM}}$ (v10.2.1, ESRI Inc.) with the effigis $^{\mathrm{TM}}$ OnPOZ GNSS Driver. We drove the tags forty times across the geofences in a car at the mean flight speed recorded from the condor $(14 \mathrm{~km} / \mathrm{h})$.

\section{Results}

The geofence tags provided highly accurate location data and transmitted SMS alert messages within a few minutes of crossing a virtual geofence boundary. The planar 2D accuracy of the two test GSM-GPS tags deviated from the DGPS flight path by a mean of $4.4 \mathrm{~m}( \pm 0.5 \mathrm{SE})$ and $2.1 \mathrm{~m}( \pm 0.6 \mathrm{SE})$, respectively. The vertical $3 \mathrm{D}$ accuracy of the test unit locations deviated by $27.2 \mathrm{~m}( \pm 0.1 \mathrm{SE})$ and $42.6 \mathrm{~m}( \pm 0.6 \mathrm{SE})$. Because the GPS fix rate had to first change from the normal $15-\mathrm{min}$ interval to $30 \mathrm{~s}$ once the tags crossed the first outer virtual boundary, it took longer to receive an SMS alert after the tags first crossed the outer geofence compared to when they crossed the inner second geofence. Hence, the timing of the initial SMS alert could range from 1 to 15 min depending on where the tag was during its fix cycle. The mean time that we received an SMS alert after we flew two the tags across the outer geofence was 9:14 $\mathrm{min}( \pm 1 \mathrm{~min} \mathrm{SE})$. The mean time that we received an SMS alert after we flew two the tags across the inner geofence was 1:17 min ( \pm 16 s SE) (Fig. 4). Consequently, we recommend that users install a minimum of two geofences around a wind farm, with an outer zone acting as a buffer to trigger the higher location fix rate function and corresponding reduction in alert message delays. We also received SMS alerts from the units on average a minute faster when we flew across the geofence boundaries compared to when we drove the units across the geofences. The mean time 


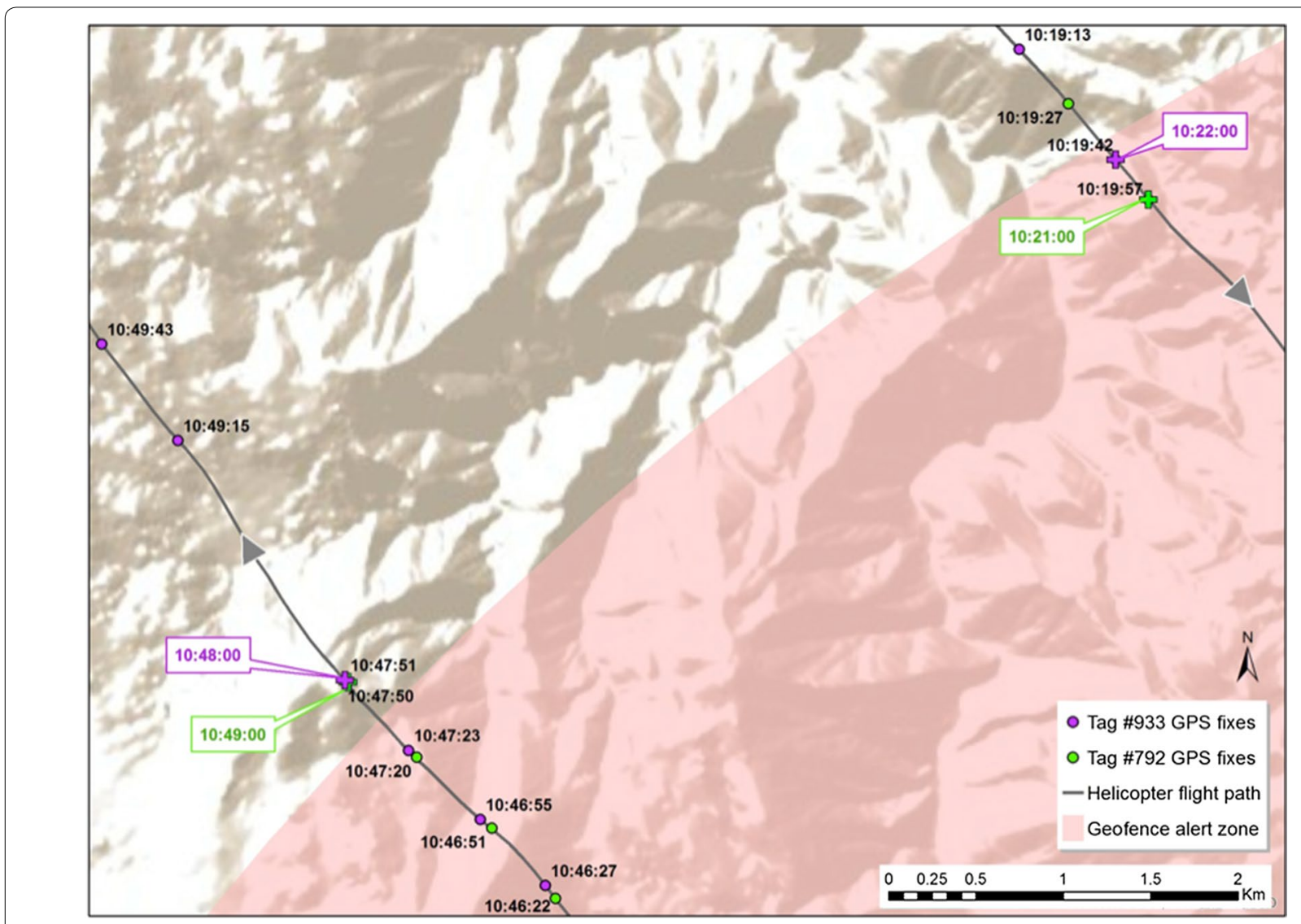

Fig. 4 Timing and locations of GPS fixes and SMS alerts received during geofence field trials. Flight path of the helicopter used to field-test the performance of the geofence transmitters indicated by the black line with directional arrows. GPS location fixes from the two transmitters (purple and green points) are labeled with the time each fix was acquired. Banner labels show the times and locations that SMS alert messages were received after the transmitters crossed the $20 \mathrm{~km}$ geofence alert zone (red shaded region)

that we received an SMS alert after we drove two the tags across the inner geofence was 2:18 min ( $\pm 37 \mathrm{~s} \mathrm{SE})$ compared to the mean alert time of $1: 17 \mathrm{~min}( \pm 16 \mathrm{~s} \mathrm{SE})$ when we flew. Higher altitudes may quicken response times by providing better access to the GPS satellite constellation and cellular communication networks.

A condor flying at the $15 \mathrm{~km} / \mathrm{h}$ mean flight speed recorded from the tracked Baja population and flying directly towards the ESJWP site would take around $2 \mathrm{~h}$ to reach the closest wind turbine after it crossed the outer boundary of the $40 \mathrm{~km}$ geofence zone and triggered an alert. The condor that flew across the ESJWP site in 2007 would have taken between 3 and $4 \mathrm{~h}$ to reach the closest turbines after it flew across the $40 \mathrm{~km}$ geofence boundary. If this bird had flown directly towards the ESJWP at its maximum recorded flight speed of $47 \mathrm{~km} / \mathrm{h}$ for its entire flight path it would have taken 43-46 min to reach the turbines after it had triggered the first alert. In the unlikely event that a telemetered condor flew directly towards the ESJWP site at a sustained speed of $100 \mathrm{~km} / \mathrm{h}$ it would still not reach the closest wind turbine until 20-22 min had passed since it triggered the first geofence SMS alert.

\section{Discussion}

Our integrated geofence biotelemetry system will provide conservation managers and wind farm operators with sufficient warning and time to implement appropriate mitigative actions to prevent avian collision mortalities associated with wind turbine collisions. The flexibility of this system will enable users to customize the locations and dimensions of their geofences and associated alert settings to meet the management challenges specific to each wind energy development and the movement behaviors of species of concern. Users must carefully consider the location and dimensions of their geofences if the system is to provide reliable alerts. For example, geofences deployed to provide alerts of fast flying eagles will have to be set apart at greater distances around a wind farm than those set to provide alerts of slower flying cranes. 
Current limitations to this alert system include its weight (which precludes its deployment on bats and small birds), the solar power system (which generally restricts operation to daytime without long periods of inclement weather) and the necessity of having to capture birds to fit them with the biotelemetry system and recapture birds whose telemetry units need replacing. For example, a large proportion of free-ranging California condors are already telemetered and condors are relatively easy to recapture, so this system can be easily incorporated into existing tracking programs. In contrast, the cost of telemetering a meaningful sample of other threatened species such as golden eagles will have to be carefully weighed against the projected collision impact risk posed by specific wind farms. The performance of the system may also be impeded if GSM network coverage in remote regions where the units are deployed is very patchy, although additional coverage is often installed around wind energy sites during construction. Much of the technology that has been developed and incorporated into this geofence system is cutting-edge and novel, so its performance will not be able to be truly gauged until it has been successfully deployed across multiple species and field settings. Despite these limitations, we feel it offers a highly promising and cost-effective solution to mitigating avian collisions with wind turbines.

The geofence tags currently cost $\$ 2.5 \mathrm{k}$ each with $\$ 300$ annual data acquisition fees per unit. The system does not require the installation of additional infrastructure, such as towers or trailers, which can make it highly cost-effective compared to traditional large-scale radar and VHF detection systems that cost between $\$ 200$ and $\$ 500 \mathrm{k}$ to deploy at each wind farm. The geofence system also enables the movements of individual telemetered birds to be monitored at GPS-level accuracy in near real time anywhere on Earth, compared to passive radar and VHF systems that can only detect birds from 30 to $50 \mathrm{~km}$ at low accuracies and can be severely reduced in performance by the steep terrain that typically surrounds wind energy sites [20, 21]. Projected enhancements to this system include a normal fix rate $<15$ min to reduce the timing of the first alert SMS as well as weight reductions to enable the units to be deployed on a wider range of smaller species. Future iterations of this geofence alert system may also include integration into automated shutdown systems for turbines, integration into automated deterrent systems such as light and sound arrays, and the inclusion of behavioral aversion systems such as buzzers in the transmitter.

\section{Conclusions}

Despite its promise as an environmentally friendly and renewable energy source, the direct impacts that wind energy developments have on avifauna populations through mortalities from wind turbine strikes are increasingly documented. Bird collision mortality at wind facilities will likely increase with further wind energy development in the coming decades as nations pursue greenhouse gas emission targets. The total amount of bird mortality caused by wind farms is non-trivial; hence, there is an urgent need for new technological solutions to minimize collision risk. Our autonomous geofence alert system presents an innovative and cost-effective biotelemetry approach to preventing collisions by combining: (1) GPS level accuracy; (2) high location fix sampling rates; (3) location data received in near real time, and; (4) automated SMS alerts from integrated and flexible virtual boundaries. Our system will provide conservation managers and wind farm operators with sufficient warning and time to implement appropriate mitigative actions to prevent avian collision mortalities associated with wind turbine collisions.

\section{Abbreviations}

GPS: global positioning system; GSM: global system for mobile communications; SMS: short message service; DGPS: differential global positioning system; GNSS: global navigation satellite system; ESJWP: Energía Sierra Juárez Wind-energy Project.

\section{Authors' contributions}

JS conceived this project, designed and conducted field tests, summarized the data, and wrote the manuscript. AM and ML designed and developed the GSM-GPS tags, geofence technology and programming. RS provided managerial and scientific oversight and gave final approval of the version to be published. All authors read and approved the final manuscript.

\section{Author details}

${ }^{1}$ San Diego Zoo Institute for Conservation Research, Escondido, CA, USA. ${ }^{2}$ Cellular Tracking Technologies LLC, Somerset, PA, USA.

\section{Acknowledgements}

We acknowledge the following California condor collaborators and funding agencies: United States Fish and Wildlife Service, Instituto Nacional de Ecologia, Comision Nacional Para El Conocimiento y Uso de la Biodiversidad, Secretaria de Medio Ambiente y Recursos Naturales, Wildcoast/Costasalvaje, Michael Wallace, Allyson Walsh, Lisa Nordstrom and the San Diego Zoo Global condor field team. Funding support for this project was generously provided by the Bailey Wildlife Foundation. Research on California condors was approved by the United States Fish and Wildlife Service, the San Diego Zoo IACUC animal welfare committee (Project ID\#11-014) and the Instituto Nacional de Ecologia, Mexico.

\section{Competing interests}

Andrew McGann is a product specialist at Cellular Tracking Technologies. Michael Lanzone is the CEO and main developer of the product line at Cellular Tracking Technologies. San Diego Zoo Global has previously received funding support for its California condor recovery program from Sempra Inc., the parent company of IEnova.

Received: 23 December 2014 Accepted: 24 September 2015 Published online: 13 October 2015

\section{References}

1. Premalatha M, Abbasi T, Abbasi S. Wind energy: increasing deployment, rising environmental concerns. Renew Sustain Energy Rev. 2014;31:270-88. 
2. Arnett EB, Brown W, Erickson WP, Fiedler JK, Hamilton BL, Henry TH, Jain A, Johnson GD, Kerns J, Koford RR. Patterns of bat fatalities at wind energy facilities in North America. J Wildl Manag. 2008;72:61-78.

3. Marques AT, Batalha H, Rodrigues S, Costa H, Pereira MJR, Fonseca C, Mascarenhas M, Bernardino J. Understanding bird collisions at wind farms: an updated review on the causes and possible mitigation strategies. Biol Conserv. 2014;179:40-52.

4. Erickson WP, Wolfe MM, Bay KJ, Johnson DH, Gehring JL. A comprehensive analysis of small-passerine fatalities from collision with turbines at wind energy facilities. PLoS One. 2014;9:e107491.

5. Kuvlesky WP, Brennan LA, Morrison ML, Boydston KK, Ballard BM, Bryant FC. Wind energy development and wildlife conservation: challenges and opportunities. J Wildl Manag. 2007;71:2487-98.

6. Piorkowski MD, Farnsworth AJ, Fry M, Rohrbaugh RW, Fitzpatrick JW, Rosenberg KV. Research priorities for wind energy and migratory wildlife. J Wildl Manag. 2012;76:451-6.

7. American Wind Wildlife Institute (AWWI). Wind turbine interactions with wildlife and their habitats: a summary of research results and priority questions. 2015. https://awwi.org/resources/summary-of-wind-wildlifeinteractions-2/\#section-summary-of-windwildlife-interactions. Accessed 31 May 2015.

8. Cagnacci F, Boitani L, Powell RA, Boyce MS. Animal ecology meets GPSbased radiotelemetry: a perfect storm of opportunities and challenges. Philos Trans R Soc B Biol Sci. 2010;365:2157-62.

9. Loss SR, Will T, Marra PP. Estimates of bird collision mortality at wind facilities in the contiguous United States. Biol Conserv. 2013;168:201-9.

10. Katzner T, Smith BW, Miller TA, Brandes D, Cooper J, Lanzone M, Brauning D, Farmer C, Harding S, Kramar DE. Status, biology, and conservation priorities for North America's eastern Golden Eagle (Aquila chrysaetos) population. Auk. 2012;129:168-76.

11. Pagel JE, Kritz KJ, Millsap BA, Murphy RK, Kershner EL, Covington S. Bald eagle and golden eagle mortalities at wind energy facilities in the contiguous United States. J Raptor Res. 2013;47:311-5.
12. Ogada DL, Keesing F, Virani MZ. Dropping dead: causes and consequences of vulture population declines worldwide. Ann N Y Acad Sci. 2012;1249:57-71.

13. De Lucas M, Janss GF, Whitfield DP, Ferrer M. Collision fatality of raptors in wind farms does not depend on raptor abundance. J Appl Ecol. 2008:45:1695-703.

14. Jachowski D, Slotow R, Millspaugh J. Good virtual fences make good neighbors: opportunities for conservation. Anim Conserv. 2014;17:187-96

15. Sheppard JK, Walenski M, Wallace MP, Velazco JJV, Porras C, Swaisgood RR. Hierarchical dominance structure in reintroduced California condors: correlates, consequences, and dynamics. Behav Ecol Sociobiol. 2013;67:1227-38

16. Tracey JA, Sheppard J, Zhu J, Wei F, Swaisgood RR, Fisher RN. Movementbased estimation and visualization of space use in 3D for wildlife ecology and conservation. PLoS One. 2014;9:e101205

17. Reaser L, Mauerman D, Díaz-Bautista A. The Sempra Baja Wind Project Energía Sierra Juarez: an economic and comprehensive analysis for the Cali-Baja Mega-Region. Fermanian Business and Economic Institute, Point Loma Nazarene University. 2012. http://www.pointloma.edu/sites/ default/files/filemanager/Fermanian_Business_Economic_Institute/ Economic_Reports/Sempra_sierra_juarez_V3.pdf. Accessed 1 Dec 2014

18. Subramanian M. An ill wind. Nature. 2012;486:310-1.

19. American Wind Energy Association (AWEA). Anatomy of a Wind Turbine. 2014. http://www.awea.org/Resources/Content. aspx?ltemNumber=5083. Accessed 31 May 2015.

20. Normandeau Associates. Remote Condor Observation Network (ReCON ${ }^{\top M}$ ). 2014. http://www.normandeau.com/pages/technology/ recon.asp. Accessed 1 Nov 2014.

21. Gerringer MB. Evaluation of an avian radar system. MSc. Indiana State University, Department of Biology. 2013.

\section{Submit your next manuscript to BioMed Central and take full advantage of:}

- Convenient online submission

- Thorough peer review

- No space constraints or color figure charges

- Immediate publication on acceptance

- Inclusion in PubMed, CAS, Scopus and Google Scholar

- Research which is freely available for redistribution

Submit your manuscript at 